\title{
Comparing Neonatal Pain Responses to Intravenous and Intramuscular Injections and Effect of Non- Pharmacological Measures
}

\author{
Dr. Pearl Mary Varughese ${ }^{* 1}$, Dr. Nandita Pai ${ }^{2}$, Dr. Prakash M. ${ }^{3}$ \\ ${ }^{1}$ Pediatrics, Pediatric Specialist, KIMS Bellerose Institute of Medical Sciences Pvt. Ltd, Kottayam \\ ${ }^{2}$ Pediatrics, Senior Clinical fellow in Pediatrics, Royal London Hospital, London, United Kingdom \\ ${ }^{3}$ Assistant Professor, Department of Community Medicine, Indira Gandhi Medical College and Research \\ Institute, Pondicherry
}

*Corresponding author: Dr. Pearl Mary Varughese; pearlmaryvar@gmail.com

Received 22 December 2020; $\quad$ Accepted 06 January 2020;

Published 08 January 2021

\begin{abstract}
Background: Neonatal pain responses have been ignored for long, in spite of many pharmacological and non- pharmacological proven methods. Non pharmacological measures like breast feeding, non- nutritive sucking or glucose solutions are easily available, affordable and readily acceptable methods. Methods: 190 babies were compared for their responses to both intravenous pre discharge blood sampling and birth dose of hepatitis B vaccine. They were randomly divided into three groups - expressed breast milk (64 babies), $2 \mathrm{ml} 10 \%$ dextrose solution via syringe (63 babies), and non- nutritive sucking with $25 \%$ dextrose (63 babies). The response to each procedure was recorded in terms of cry duration and using NIPS scale. Kruskal Wallis test, Wilcoxon Signed Ranks test, Mann Whitney U test, ANOVA were used find the association between quantitative variables whereas McNemar test, McNemar-Bowker test and Chi-square test were used for qualitative variables. Results: The baseline demographic data of all the groups were comparable. The NIPS scores were reduced significantly in all the 3 groups in both the procedures. Babies on non-nutritive sucking with dextrose had the least scores, followed by babies on dextrose and finally those on expressed breast milk for both the procedures. All the 3 groups had significant variations in $\mathrm{HR}$ and $\mathrm{SPO}_{2}$ from baseline and at $3^{\text {rd }}$ min, the variations were reducing with group 3 showing the maximum potential for quick stabilisation in both the procedures. The cry duration was significantly lower in group 3 in both the invasive procedures. Conclusion: Neonatal pain responses were least among the neonates provided with non- nutritive sucking with $25 \%$ dextrose during the intra-venous procedure and intra-muscular procedure. Non- nutritive sucking with $25 \%$ dextrose can be recommended as effective, reliable and useful method for decreasing the pain responses during the procedures.
\end{abstract}

Keywords: Dextrose, non- nutritive sucking, Hepatitis B vaccine, neonatal pain

\section{Introduction}

Neonates are subject to multiple invasive painful procedures following birth that are deemed necessary, like vaccinations. There are multiple pain alleviating methods available - both pharmacological and non- pharmacological; but they are seldom routinely prescribed or followed by the hospital staff and parents. For many years, the medical community was under the myth that babies were insensitive to pain due to their immature pain pathways. But this has been proved wrong ${ }^{[1]}$. Preterm infants in comparison to term babies have a lower pain threshold not because their nervous system is immature, but because the descending inhibitory fibres have not fully matured ${ }^{[2]}$. Therefore, while the new-born's nervous system still has room for growth after birth, it is fully intact and capable of transmitting nociceptive responses from the sensory receptors in the skin to the dorsal horn in the brain ${ }^{[3]}$. The other reason for the absence of intervention could be because parents are not aware or because of busy outpatient settings. Repeated traumatic experiences during neonatal period can lead to neurodevelopmental and behavioural damage, with detrimental consequences over both the short and long term ${ }^{[4,5]}$. Studies conducted in developing countries demonstrated that most infants still underwent painful procedures without any analgesic intervention ${ }^{[6]}$. According to Anand et.al only less than $35 \%$ of almost 20,000 painful procedures involved some form of analgesia for the infant ${ }^{[2]}$. It has been rightly said that to relieve pain, one must first realise when the neonate is in pain ${ }^{[7]}$. Nonpharmacologic interventions to reduce pain should be sought 
whenever possible because of their effectiveness, low cost and safety ${ }^{[8]}$.

There are many studies which demonstrate the use of non pharmacological measures following either one procedure, either intravenous or intramuscular. This study was one of the few that shows the pain responses to both the invasive procedures using three non- pharmacological methods

\section{Methods}

This is a prospective study conducted in a secondary level hospital from June 2018- December 2018. Inclusion criteria included all babies delivered in our hospital during this time period and above 36 weeks gestational age and above $2500 \mathrm{~g}$ birth weight. Exclusion criteria included babies requiring NICU admission, babies with congenital anomalies or congenital cardiac defects, babies on antibiotics. In babies where more than 2 failed attempts were seen for intravenous sampling, they were again taken for blood sampling only after a minimum period of six hours. The protocol was approved by the hospital ethics board and informed consent was obtained from the mothers in their own language.

The enrolled neonates were randomized using sequentially numbered and sealed envelopes method which is an easy, cheap and reliable method of maintaining allocation concealment. Enrolled cases were divided into 3 groups using this method. The person performing randomization was not involved in the study beyond this. The first observer opened one sealed envelope for each baby and recruited that baby to 1 of 3 groups depending upon the group mentioned in that envelope. All the interventions were started 2 minutes before the procedure and continued till 2 minutes after that.

Three groups mentioned above along with their suggested mechanism of action are as:(1) Group 1, Expressed breast milk: New-borns in this group were given $2 \mathrm{ml}$ of expressed breast milk given through mouth via sterile syringe (2) Group 2, 25\% dextrose: $2 \mathrm{~mL}$ of $25 \%$ dextrose solution was given through mouth with sterile syringe and (3) Group 3, NNS with 25\% dextrose: New-borns were made to suck a gloved finger after dipping it in $25 \%$ dextrose.
It is the hospital protocol to check serum bilirubin levels at 48 hours of life in all babies. The birth vaccines (OPV, BCG and Hepatitis B) are usually given on day 3 or before discharge. The babies are taken to the treatment room for both the procedures. The infants are laid supine on the examination table. The site chosen for all the venepunctures were the dorsum of the hand using a $23 \mathrm{~mm}$ gauge needle and Hepatitis B birth dose was given on the anterolateral aspect of the right thigh. There is a trained nurse for giving the birth vaccines.

These two invasive procedures were never done simultaneously and there was a time gap of at least 12-24 hours between both the procedures. Before each intervention, the nurses made sure that the babies were breastfed at least 30-60 minutes before the procedure. There were two trained nurses to monitor for the pain scales in terms of cry duration and facial reactions. Video recording was not done. Heart rate and oxygen saturation for all the babies were recorded by means of ECG monitor connected to the babies for a period of 5 minutes. Total of three recordings were taken, one was 2 minutes before the analgesic intervention, during the injection phase (IM/IV) and third reading was taken 2 minutes after the injection (IM/IV). The primary investigator was not involved in pain assessment to avoid investigator bias and only assisted in training the nurses, in helping in connecting the babies to the ECG monitor before the procedures. The 5 minutes timer was set up in the room and was switched on before the analgesic intervention for each baby.

Pain is subjective and must be assessed indirectly in neonates through changes in physiological or behavioural parameters ${ }^{[9]}$. That is the reason we assessed pain using the Neonatal Infant Pain Scale (NIPS), the heart rate and oxygen saturation, and the description of the non-pharmacological measure if any. The NIPS has six pain indicators, one physiological and five behavioural, including facial expression, crying, movement of arms and legs, sleep/alertness state and respiratory pattern. The scale scores vary between zero, one and two points, depending on the characteristic presented. The minimum score is zero, and the maximum score is seven. The pain is characterized by the sum of points greater than or equal to four ${ }^{[10]}$ as shown in table 1. NIPS score was used just before the IM/ IV injection and then again 2 minutes after the injection.

Table 1: NIPS pain scale

\begin{tabular}{|l|l|l|l|}
\hline Parameters & 0 Point & 1 Point & 2 Point \\
\hline Facial expressopn & Relaxed & Grimace & - \\
\hline Cry & No Cry & Whimper & Vigorous Crying \\
\hline Breathing Pattern & Relaxed & Change in breathing & - \\
\hline Arms & Relaxed & Flexed/extended & - \\
\hline Legs & Relaxed & Flexed/extended & - \\
\hline State of Arousal & Speeping/Awake & Fussy & - \\
\hline
\end{tabular}

Pin level: $0-2$ point $=$ No pain, $3-4$ points $=$ Moderate pain, $>4$ points $=$ Severe pain

Data was entered in MS Excel and analysis was done using SPSS version 20. Shapiro Wilk test was used to assess the normality of the data. Frequency \& percentage was used to represent the qualitative data. Mean \& standard deviation was used to represent the quantitative data if it followed normal distribution. Chi-square test was used to find the association between the qualitative data. McNemar test/ McNemar-Bowker test was used to determine whether there was any difference on a categorical dependent variable between two related groups. ANOVA test with Post hoc
Bonferroni test was used to find the association between the quantitative data, if data followed normality. Kruskal Wallis test, Wilcoxon Signed Ranks test, Mann Whitney U test was used to find the association between the quantitative data, if it was ordinal data or data followed non normal distribution. $\mathrm{p}$ value $<0.05$ was considered as significant

\section{Results}


Table 2: Demographic data of the newborns

\begin{tabular}{|c|c|c|c|c|}
\hline VARIABLE & $\begin{array}{l}\text { Group } 1 \\
\mathrm{~N}(\%) \text { or Mean }+ \text { SD }\end{array}$ & $\begin{array}{l}\text { Group } 2 \\
\mathrm{~N}(\%) \text { or Mean } \pm \mathrm{SD}\end{array}$ & $\begin{array}{l}\text { Group } 3 \\
\mathrm{~N}(\%) \text { or Mean }+ \text { SD }\end{array}$ & p value \\
\hline \multicolumn{5}{|l|}{ SEX OF BABY } \\
\hline FEMALE & $24(37.5)$ & $34(54.0)$ & $34(54.0)$ & \multirow[b]{2}{*}{0.100} \\
\hline MALE & $40(62.5)$ & $29(46.0)$ & $29(46.0)$ & \\
\hline \multicolumn{5}{|l|}{ BIRTH WEIGHT } \\
\hline$<2500 \mathrm{~g}$ & $2(3.1)$ & $2(3.2)$ & $2(3.2)$ & \multirow[b]{4}{*}{0.766} \\
\hline $2500-2999 \mathrm{~g}$ & $28(43.8)$ & $27(42.9)$ & $35(55.6)$ & \\
\hline $3000-3499 \mathrm{~g}$ & $26(40.6)$ & $28(44.4)$ & $22(34.9)$ & \\
\hline$>3500 \mathrm{~g}$ & $8(12.5)$ & $6(9.5)$ & $4(6.3)$ & \\
\hline BIRTH WEIGHT & $3.042 \pm 0.4044$ & $3.036 \pm 0.3840$ & $2.939 \pm 0.3423$ & $0.312^{*}$ \\
\hline \multicolumn{5}{|l|}{ MODE OF DELIVERY } \\
\hline LSCS & $24(37.5)$ & $23(36.5)$ & $18(28.6)$ & \multirow[b]{2}{*}{0.510} \\
\hline SVD & $40(62.5)$ & $40(63.5)$ & $45(71.4)$ & \\
\hline \multicolumn{5}{|l|}{ GESTATIONAL AGE } \\
\hline PRETERM & $5(7.8)$ & $2(3.2)$ & $9(14.3)$ & \multirow[b]{2}{*}{0.079} \\
\hline TERM & $59(92.2)$ & $61(96.8)$ & $54(85.7)$ & \\
\hline \multicolumn{5}{|c|}{$\begin{array}{l}\text { WEIGHT ACCORDING TO GESTATIONAL } \\
\text { AGE }\end{array}$} \\
\hline Appropriate for gestational age (AGA) & $52(81.2 \%)$ & $53(84.1)$ & $53(84.1)$ & \multirow{3}{*}{0.877} \\
\hline Large for Gestational age (LGA) & $1(1.6 \%)$ & $1(1.6)$ & $0(0.0)$ & \\
\hline Small for Gestational age (SGA) & $11(17.2)$ & $9(14.3)$ & $10(15.9)$ & \\
\hline
\end{tabular}

*Kruskal Wallis Test; Chi-square test

The table 2 shows the demographic distribution of the new born data. The baseline data of all the three groups were similar ( $\mathrm{p}$ value $>0.05$ ).

Table 3: Table showing behaviuoral and physiological responses of babies in the groups before and after intravenous procedure

\begin{tabular}{|c|c|c|c|c|c|c|c|c|}
\hline \multirow[t]{2}{*}{ Variable } & \multicolumn{2}{|l|}{$\begin{array}{l}\text { GROUP } 1 \\
(\mathrm{~N}=64)\end{array}$} & \multicolumn{2}{|l|}{$\begin{array}{l}\text { GROUP } 2 \\
(\mathrm{~N}=63)\end{array}$} & \multicolumn{2}{|l|}{$\begin{array}{l}\text { GROUP } 3 \\
(\mathrm{~N}=63)\end{array}$} & \multicolumn{2}{|l|}{ p value $^{\#}$} \\
\hline & $\begin{array}{l}\text { BEFORE N } \\
(\%)\end{array}$ & $\begin{array}{l}\text { AFTER N } \\
(\%)\end{array}$ & $\begin{array}{l}\text { BEFORE } \\
\text { N (\%) }\end{array}$ & $\begin{array}{l}\text { AFTER N } \\
(\%)\end{array}$ & $\begin{array}{l}\text { BEFORE } \\
\text { N }(\%)\end{array}$ & $\begin{array}{l}\text { AFTER N } \\
(\%)\end{array}$ & Before & After \\
\hline \multicolumn{9}{|l|}{ FACIAL EXPRESSION } \\
\hline Contracted & $25(39.1)$ & $28(43.8)$ & $19(30.2)$ & $11(17.5)$ & $21(33.3)$ & $3(4.8)$ & \multirow[t]{2}{*}{0.563} & \multirow[t]{2}{*}{$<0.001$} \\
\hline Relaxed & $39(60.9)$ & $36(56.3)$ & $44(69.8)$ & $52(82.5)$ & $42(66.7)$ & $60(95.2)$ & & \\
\hline p value* & \multicolumn{2}{|l|}{0.690} & \multicolumn{2}{|l|}{0.039} & \multicolumn{2}{|l|}{$<0.001$} & & \\
\hline \multicolumn{9}{|l|}{ CRYING } \\
\hline Absent & $13(20.3)$ & $12(18.8)$ & $19(30.2)$ & $39(61.9)$ & $25(39.7)$ & $45(71.4)$ & \multirow[t]{3}{*}{0.004} & \multirow[t]{3}{*}{$<0.001$} \\
\hline Mumble & $37(57.8)$ & $51(79.7)$ & $37(58.7)$ & $24(38.1)$ & $37(58.7)$ & $18(28.6)$ & & \\
\hline Vigorous & $14(21.9)$ & $1(1.6)$ & $7(11.1)$ & $0(0.0)$ & $1(1.6)$ & $0(0.0)$ & & \\
\hline p value ${ }^{@}$ & \multicolumn{2}{|l|}{0.003} & \multicolumn{2}{|l|}{ NA } & \multicolumn{2}{|l|}{ NA } & & \\
\hline \multicolumn{9}{|l|}{ BREATHING } \\
\hline Relaxed & $52(81.3)$ & $64(100.0)$ & $56(88.9)$ & $63(100.0)$ & $61(96.8)$ & $63(100.0)$ & \multirow[t]{2}{*}{0.020} & \multirow[t]{2}{*}{ NA } \\
\hline Altered & $12(18.8)$ & $0(0.0)$ & $7(11.1)$ & $0(0.0)$ & $2(3.2)$ & $0(0.0)$ & & \\
\hline p value* & \multicolumn{2}{|l|}{ NA } & \multicolumn{2}{|l|}{ NA } & \multicolumn{2}{|l|}{ NA } & & \\
\hline \multicolumn{9}{|l|}{ ARMS } \\
\hline Flexed/extended & $26(40.6)$ & $2(3.1)$ & $24(38.1)$ & $0(0.0)$ & $17(27.0)$ & $0(0.0)$ & \multirow[t]{2}{*}{0.232} & \multirow[t]{2}{*}{0.137} \\
\hline Relaxed & $38(59.4)$ & $62(96.9)$ & $39(61.9)$ & $63(100.0)$ & $46(73.0)$ & $63(100.0)$ & & \\
\hline $\mathrm{p}$ value* & \multicolumn{2}{|l|}{$<0.001$} & \multicolumn{2}{|l|}{ NA } & \multicolumn{2}{|l|}{ NA } & & \\
\hline LEGS & & & & & & & & \\
\hline Flexed/extended & $26(40.6)$ & $2(3.1)$ & $24(38.1)$ & $0(0.0)$ & $17(27.0)$ & $0(0.0)$ & 0.232 & 0.137 \\
\hline Relaxed & $38(59.4)$ & $62(96.9)$ & $39(61.9)$ & $63(100.0)$ & $46(73.0)$ & $63(100.0)$ & & \\
\hline p value* & $<0.001$ & & NA & & NA & & & \\
\hline CONSCIOUS STATE & & & & & & & & \\
\hline Sleeping/quiet & $49(76.6)$ & $32(50.0)$ & $56(88.9)$ & $55(87.3)$ & $55(87.3)$ & $60(95.2)$ & 0.116 & $<0.001$ \\
\hline Uncomfortable & $15(23.4)$ & $32(50.0)$ & $7(11.1)$ & $8(12.7)$ & $8(12.7)$ & $3(4.8)$ & & \\
\hline p value* & 0.002 & & 1.000 & & 0.180 & & & \\
\hline HEART RATE & & & & & & & & \\
\hline $100-119$ & $26(40.6)$ & $19(29.7)$ & $37(58.7)$ & $31(49.2)$ & $29(46.0)$ & $24(38.1)$ & 0.112 & 0.207 \\
\hline $120-139$ & $38(59.4)$ & $43(67.2)$ & $26(41.3)$ & $29(46.0)$ & $34(54.0)$ & $36(57.1)$ & & \\
\hline $140-159$ & $0(0.0)$ & $2(3.1)$ & $0(0.0)$ & $3(4.8)$ & $0(0.0)$ & $3(4.8)$ & & \\
\hline p value ${ }^{@}$ & NA & & NA & & NA & & & \\
\hline
\end{tabular}




\begin{tabular}{|c|c|c|c|c|c|c|c|c|}
\hline \multicolumn{9}{|c|}{ OXYGEN SATURATION } \\
\hline $91-95$ & $0(0.0)$ & $6(9.4)$ & $0(0.0)$ & $3(4.8)$ & $0(0.0)$ & $4(6.3)$ & NA & 0.578 \\
\hline 96-100 & $64(100.0)$ & $58(90.6)$ & $63(100.0)$ & $60(95.2)$ & $63(100.0)$ & $59(93.7)$ & & \\
\hline p value* & \multicolumn{2}{|l|}{ NA } & \multicolumn{2}{|l|}{ NA } & \multicolumn{2}{|l|}{ NA } & & \\
\hline \multicolumn{9}{|l|}{ NIPS } \\
\hline (0-2) No pain & 34 (53.1) & $42(65.6)$ & $44(69.8)$ & $58(92.1)$ & $44(69.8)$ & $61(96.8)$ & \multirow[t]{3}{*}{0.005} & \multirow[t]{3}{*}{$<0.001$} \\
\hline (3-4) Moderate & $12(18.8)$ & $21(32.8)$ & $11(17.5)$ & $5(7.9)$ & $16(25.4)$ & $2(3.2)$ & & \\
\hline$(>4)$ Severe & $18(28.1)$ & $1(1.6)$ & $8(12.7)$ & $0(0.0)$ & $3(4.8)$ & $0(0.0)$ & & \\
\hline p value ${ }^{@}$ & \multicolumn{2}{|l|}{0.001} & \multicolumn{2}{|l|}{ NA } & \multicolumn{2}{|l|}{$\mathrm{NA}$} & & \\
\hline
\end{tabular}

*McNemar Test; @McNemar-Bowker Test; \#Chi-square test.

As shown in table 3, the baseline responses were comparable in all the groups except for crying, breathing and NIPS scores category. After the intervention, facial expression and crying showed a statistically significant association since majority in the group 2 and group 3 achieved a relaxed face and absent cry. Breathing and posture was relaxed in all the groups. Hence, there was no statistically significant association.
The conscious state of the baby was important as it showed a statistically significant association since majority in the group 2 and group 3 achieved a sleeping/wake state.

The heart rate did not show any statistically significant difference in all the groups after intervention. After the intervention, NIPS score category showed a statistically significant association since majority in the group 2 and group 3 achieved no pain state.

Table 4: Table showing behaviuoral and physiological responses of babies in the groups before and after hepatits B vaccination

\begin{tabular}{|c|c|c|c|c|c|c|c|c|}
\hline \multirow[b]{2}{*}{ VARIABLE } & \multicolumn{2}{|c|}{ GROUP 1 (N=64) } & \multicolumn{2}{|c|}{ GROUP $2(\mathrm{~N}=63)$} & \multicolumn{2}{|c|}{ GROUP 3 (N=63) } & \multicolumn{2}{|c|}{ p value ${ }^{\#}$} \\
\hline & $\begin{array}{l}\text { BEFORE } \\
\text { N(\%) }\end{array}$ & $\begin{array}{l}\text { AFTER N } \\
(\%)\end{array}$ & $\begin{array}{l}\text { BEFORE } \\
\text { N (\%) }\end{array}$ & $\begin{array}{l}\text { AFTER N } \\
(\%)\end{array}$ & $\begin{array}{l}\text { BEFORE } \\
\text { N }(\%)\end{array}$ & $\begin{array}{l}\text { AFTER N } \\
(\%)\end{array}$ & Before & After \\
\hline \multicolumn{9}{|c|}{ FACIAL EXPRESSION } \\
\hline Contracted & $27(42.2)$ & $19(29.7)$ & $20(31.7)$ & $9(14.3)$ & $22(34.9)$ & $10(15.9)$ & \multirow[b]{2}{*}{0.455} & \multirow[b]{2}{*}{0.058} \\
\hline Relaxed & $37(57.8)$ & $45(70.3)$ & $43(68.3)$ & $54(85.7)$ & $41(65.1)$ & $53(84.1)$ & & \\
\hline p value* & \multicolumn{2}{|l|}{$<0.008$} & \multicolumn{2}{|l|}{$<0.001$} & \multicolumn{2}{|l|}{$<0.001$} & & \\
\hline \multicolumn{9}{|l|}{ CRYING } \\
\hline Mumble & $35(54.7)$ & $19(29.7)$ & $37(58.7)$ & $17(27.0)$ & $32(50.8)$ & $19(30.2)$ & \multirow{3}{*}{0.238} & \multirow{3}{*}{0.882} \\
\hline Absent & $15(23.4)$ & $42(65.6)$ & $18(28.6)$ & $44(69.8)$ & $24(38.1)$ & $43(68.3)$ & & \\
\hline Vigorous & $14(21.9)$ & $3(4.7)$ & $8(12.7)$ & $2(3.2)$ & $7(11.1)$ & $1(1.6)$ & & \\
\hline p value ${ }^{\Theta}$ & \multicolumn{2}{|l|}{$<0.001$} & \multicolumn{2}{|l|}{$<0.001$} & \multicolumn{2}{|l|}{0.001} & & \\
\hline \multicolumn{9}{|l|}{ BREATHING } \\
\hline Altered & $10(15.6)$ & $3(4.7)$ & $6(9.5)$ & $2(3.2)$ & $7(11.1)$ & $1(1.6)$ & \multirow[t]{2}{*}{0.549} & \multirow[t]{2}{*}{0.607} \\
\hline Relaxed & $54(84.4)$ & $61(95.3)$ & $57(90.5)$ & $61(96.8)$ & $56(88.9)$ & $62(98.4)$ & & \\
\hline p value* & \multicolumn{2}{|l|}{0.039} & \multicolumn{2}{|l|}{0.125} & \multicolumn{2}{|l|}{0.070} & & \\
\hline \multicolumn{9}{|l|}{ ARMS } \\
\hline Flexed/extended & $19(29.7)$ & $7(10.9)$ & $13(20.6)$ & $2(3.2)$ & $17(27.0)$ & $3(4.8)$ & \multirow[t]{2}{*}{0.489} & \multirow[t]{2}{*}{0.164} \\
\hline Relaxed & $45(70.3)$ & $57(89.1)$ & $50(79.4)$ & $61(96.8)$ & $46(73.0)$ & $60(95.2)$ & & \\
\hline p value* & $<0.001$ & & 0.001 & & $<0.001$ & & & \\
\hline LEGS & & & & & & & & \\
\hline Flexed/extended & $19(29.7)$ & $7(10.9)$ & $13(20.6)$ & $2(3.2)$ & $17(27.0)$ & $3(4.8)$ & 0.489 & 0.164 \\
\hline Relaxed & $45(70.3)$ & $57(89.1)$ & $50(79.4)$ & $61(96.8)$ & $46(73.0)$ & $60(95.2)$ & & \\
\hline p value* & $<0.001$ & & 0.001 & & $<0.001$ & & & \\
\hline CONSCIOUS STATE & & & & & & & & \\
\hline Sleeping/quiet & $50(78.1)$ & $55(85.9)$ & $51(81.0)$ & $54(85.7)$ & $56(88.9)$ & $61(96.8)$ & 0.253 & 0.067 \\
\hline Uncomfortable & $14(21.9)$ & $9(14.1)$ & $12(19.0)$ & $9(14.3)$ & $7(11.1)$ & $2(3.2)$ & & \\
\hline p value* & 0.227 & & 0.607 & & 0.125 & & & \\
\hline HEART RATE & & & & & & & & \\
\hline $100-119$ & $34(53.1)$ & $24(37.5)$ & $29(46.0)$ & $17(27.0)$ & $29(46.0)$ & $24(38.1)$ & 0.652 & 0.488 \\
\hline $120-139$ & $30(46.9)$ & $39(60.9)$ & $34(54.0)$ & $46(73.0)$ & $34(54.0)$ & $38(60.3)$ & & \\
\hline $140-159$ & $0(0.0)$ & $1(1.6)$ & $0(0.0)$ & $0(0.0)$ & $0(0.0)$ & $1(1.6)$ & & \\
\hline p value ${ }^{@}$ & NA & & NA & & NA & & & \\
\hline OXYGEN SATURAT & & & & & & & & \\
\hline 96-100 & $64(100.0)$ & $64(100.0)$ & $63(100.0)$ & $63(100.0)$ & $63(100.0)$ & $63(100.0)$ & NA & NA \\
\hline p value* & NA & & NA & & NA & & & \\
\hline NIPS & & & & & & & & \\
\hline (0-2) No pain & $39(60.9)$ & $51(79.7)$ & $42(66.7)$ & $55(87.3)$ & $43(68.3)$ & $58(92.1)$ & 0.511 & 0.352 \\
\hline (3-4) Moderate & $11(17.2)$ & $9(14.1)$ & $14(22.2)$ & $6(9.5)$ & $11(17.5)$ & $4(6.3)$ & & \\
\hline
\end{tabular}




\begin{tabular}{|l|l|l|l|l|l|l|l|l|}
\hline$(>4)$ Severe & $14(21.9)$ & $4(6.2)$ & $7(11.1)$ & $2(3.2)$ & $9(14.3)$ & $1(1.6)$ & & \\
\hline$p^{p}$ value $^{\Theta}$ & $<0.001$ & 0.001 & $<0.001$ & & & \\
\hline
\end{tabular}

*McNemar Test; @ McNemar-Bowker Test; \#Chi-square test.

As shown in table 4, the baseline responses were comparable in all groups and after the intervention, there was no statistically significant difference between the three groups. When before and after intervention was compared in each group using McNemar test, there was a statistically significant improvement in all the parameters except conscious state. In breathing, only group 1 showed a significant improvement after intervention. Heart rate could not be assessed using McNemar-Bowker Test. All the neonates had oxygen saturation between $96-100$ and so the statistical tests were not applicable. The NIPS scores significantly reduced in all the 3 groups after the intervention with maximum being achieved in group 3 .

Table 5: Table showing comparison of nips score in the groups before and after intravenous procedure

\begin{tabular}{|c|c|c|c|c|c|c|c|c|c|}
\hline \multicolumn{2}{|c|}{ VARIABLE } & \multicolumn{2}{|l|}{$\begin{array}{l}\text { GROUP 1 } \\
(\mathrm{N}=64)\end{array}$} & \multicolumn{2}{|l|}{$\begin{array}{l}\text { GROUP } 2 \\
(\mathrm{~N}=63)\end{array}$} & \multicolumn{2}{|l|}{$\begin{array}{l}\text { GROUP } 3 \\
(\mathrm{~N}=63)\end{array}$} & \multicolumn{2}{|c|}{ p value ${ }^{\#}$} \\
\hline & & Before & After & Before & After & Before & After & Before & After \\
\hline \multirow{2}{*}{$\begin{array}{l}\text { NIPS } \\
\text { (IV) }\end{array}$} & Median (IQR) & $1.00(4)$ & $2.00(2)$ & $1.00(2)$ & $0.00(1)$ & $1.00(3)$ & $0.00(1)$ & \multirow[t]{3}{*}{0.083} & \multirow[t]{3}{*}{$<0.001$} \\
\hline & Mean (SD) & $2.67(2.397)$ & $1.81(1.258)$ & $2.00(1.892)$ & $0.71(0.974)$ & $1.65(1.628)$ & $0.43(0.712)$ & & \\
\hline \multicolumn{2}{|c|}{ p value $\mathrm{s}^{\mathrm{s}}$} & \multicolumn{2}{|l|}{0.002} & \multicolumn{2}{|l|}{$<0.001$} & \multicolumn{2}{|l|}{$<0.001$} & & \\
\hline \multirow{2}{*}{$\begin{array}{l}\text { NIPS } \\
\text { (IM) }\end{array}$} & Median (IQR) & $1.00(3)$ & $0.00(2)$ & $1.00(3)$ & $0.00(1)$ & $1.00(3)$ & $0.00(1)$ & \multirow[t]{3}{*}{0.278} & \multirow[t]{3}{*}{0.240} \\
\hline & Mean (SD) & $2.38(2.313)$ & $1.13(1.741)$ & $1.86(1.950)$ & $0.73(1.417)$ & $1.84(2.142)$ & $0.63(1.195)$ & & \\
\hline \multicolumn{2}{|c|}{ p value $\mathrm{s}^{\mathrm{s}}$} & \multicolumn{2}{|l|}{$<0.001$} & \multicolumn{2}{|l|}{$<0.001$} & \multicolumn{2}{|l|}{$<0.001$} & & \\
\hline
\end{tabular}

\$Wilcoxon Signed Ranks Test; \#Kruskal Wallis Test.

Before and after comparison of NIPS score using Wilcoxon Signed Ranks Test revealed that all the groups had a statistically significant reduction in NIPS scores after both the invasive interventions. Kruskal Wallis Test showed that the NIPS scores were comparable/ similar in all the groups before both the invasive procedures. After the intravenous sampling, the pairwise comparison revealed the NIPS scores were least in the group 3 followed by group 2. But this was not so for the Hepatitis B vaccination. Kruskal Wallis Test (non parametric counterpart of ANOVA) revealed that there was no statistically significant difference between the NIPS score after the intervention. This showed that the NIPS scores were similar in all the groups after the intramuscular intervention.

Table 6: Total cry duration in the groups for both the interventions

\begin{tabular}{|l|l|l|l|}
\hline GROUPS & $\begin{array}{l}\text { Cry duration for } \\
\text { intravenous injection }\end{array}$ & $\begin{array}{l}\text { Cry duration for } \\
\text { intramuscular route }\end{array}$ & $\begin{array}{l}\text { Mann Whitney U } \\
\text { test p value }\end{array}$ \\
\hline GROUP 1(2ml of Expressed breast milk via syringe) & $134.61 \pm 38.496$ & $100.91 \pm 44.084$ & $<0.001$ \\
\hline GROUP 2 (2ml of 25\% dextrose via syringe) & $104.57 \pm 49.944$ & $89.21 \pm 57.194$ & 0.111 \\
\hline GROUP 3 (NNS and 25\% dextrose) & $78.41 \pm 51.710$ & $76.16 \pm 56.312$ & 0.816 \\
\hline Kruskal Wallis Test p value & $<0.001$ & 0.045 & \\
\hline
\end{tabular}

As shown in table 6 , the cry duration is statistically significant with group 3 having the least duration for both invasive procedures, followed by group 2 and last by group 1 . Compared to the

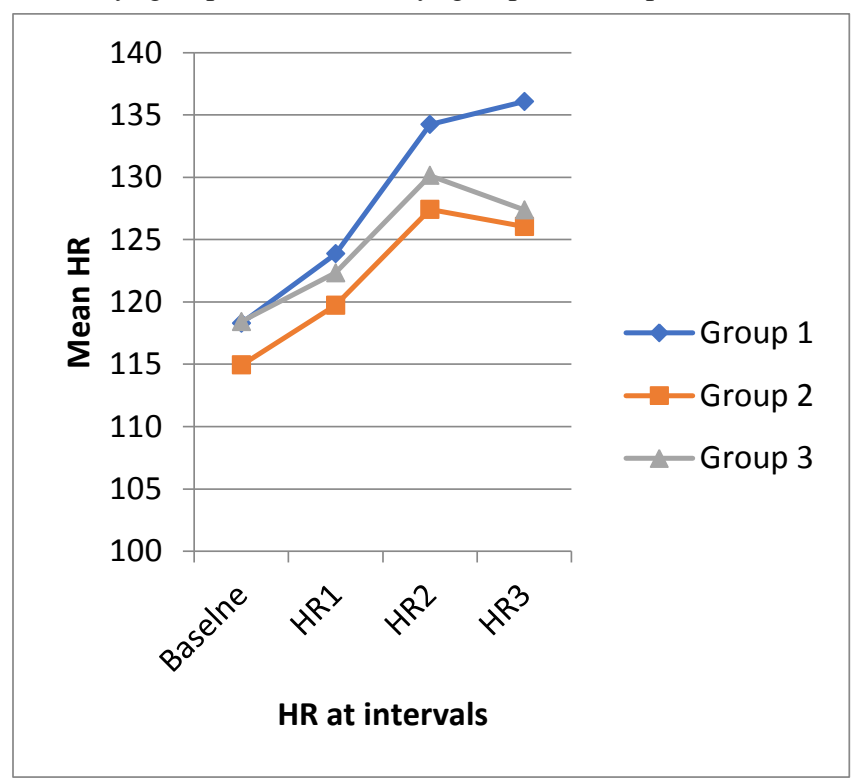

1A: INTRAVENOUS ROUTE intravenous sampling, the intramuscular Hepatitis B vaccination, had lesser cry duration in all the three groups.

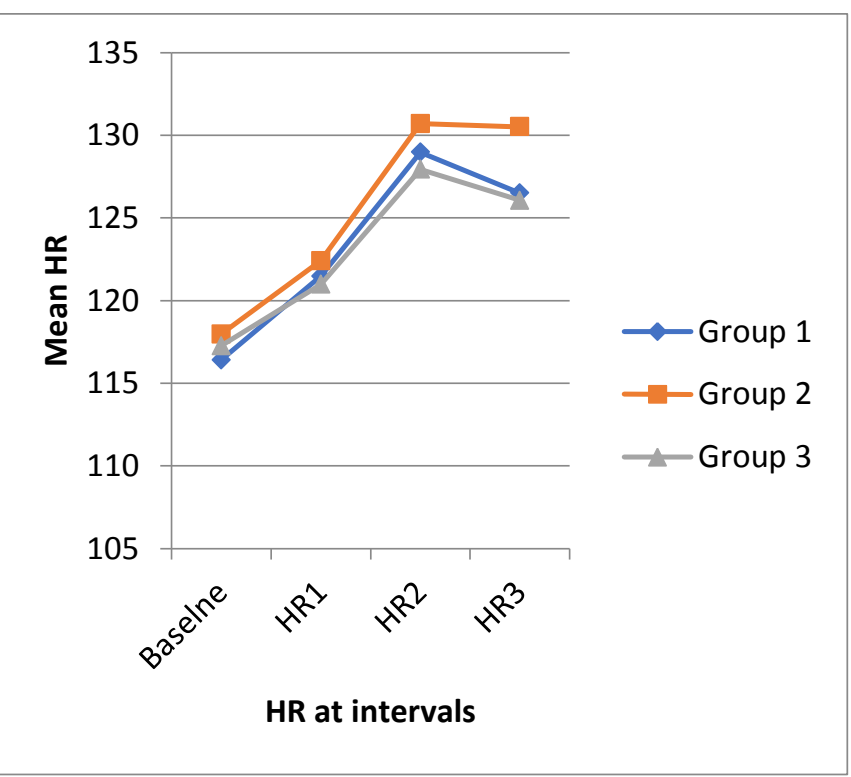

1B: INTRAMUSCULAR ROUTE

Figure 1: Trends of heart rates in the three groups for bothinterventions 
Figure 1A shows that in intravenous intervention, there was a statistically significant difference in all the intervals of HR. Post hoc Bonferroni revealed that the HR in group 1 is the higher than the group 2 and group 3 in third HR reading, taken 2 minutes after the invasive procedure. In other intervals, HR in group 1 is higher

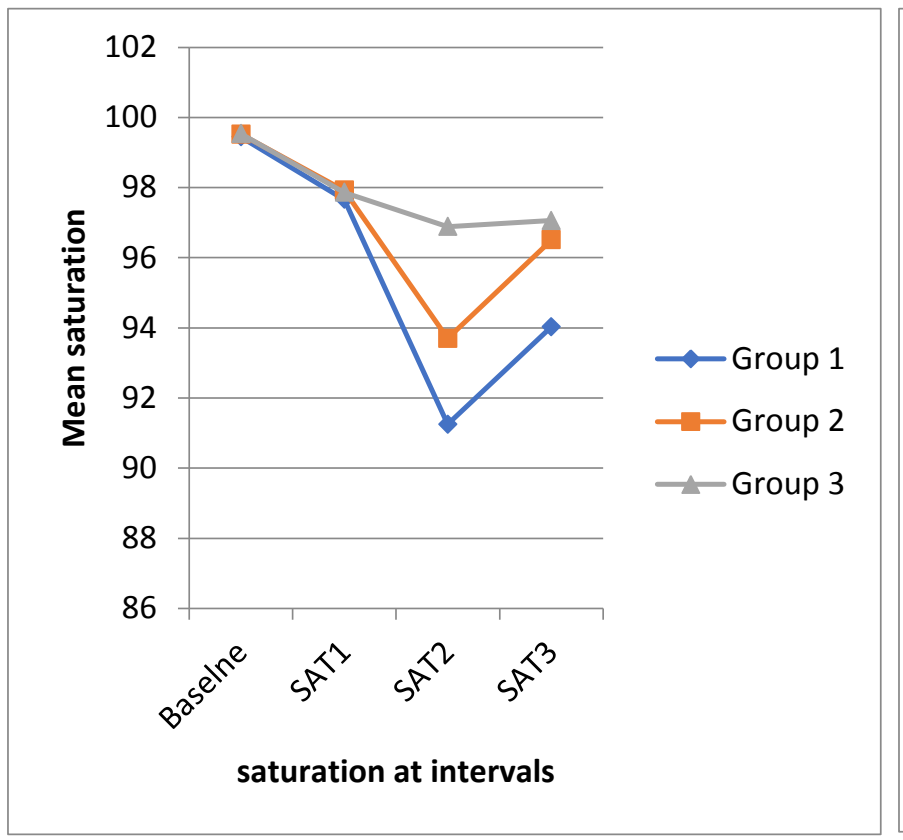

2A: INTRAVENOUS ROUTE than group 2 significantly. For the intramuscular intervention as shown in figure $1 \mathrm{~B}$, ANOVA test revealed that there was no statistically significant difference in all the intervals of HR except at HR3. In HR3, post hoc Bonferroni revealed that the HR in group 2 is the higher than the group 1 and group 3 in HR3.

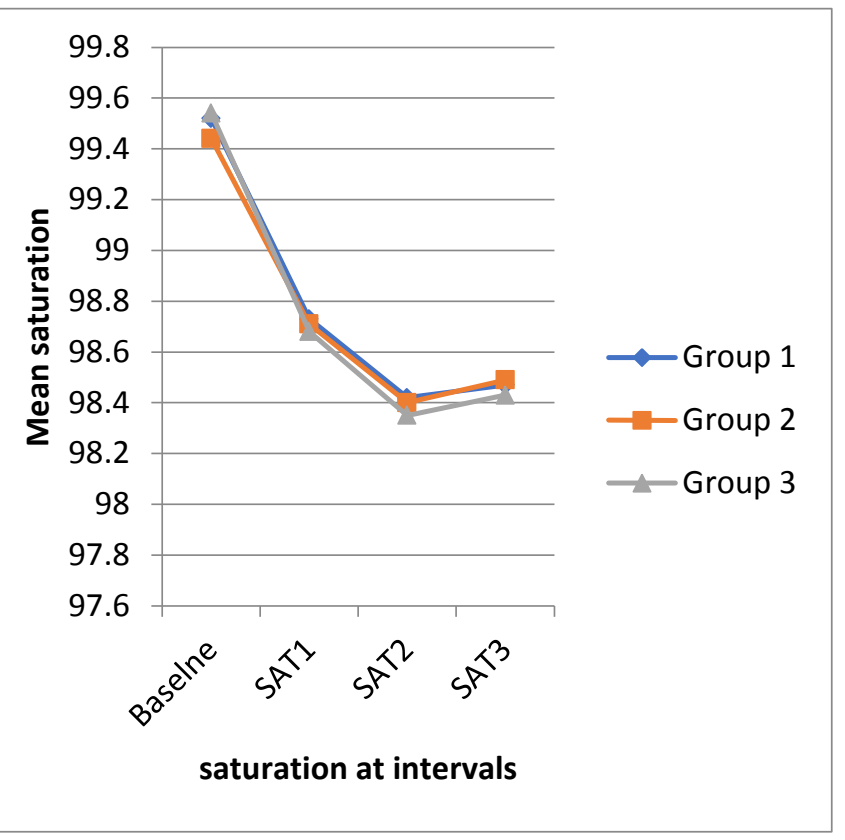

2B: INTRAMUSCULAR ROUTE

Figure 2: Trends of changes in saturation in the three groups for both interventions

As shown in figure 2A, ANOVA test revealed that there was no statistically significant difference between the groups in the baseline and first spo2 taken 2 minutes before the procedure. But the spo2 readings taken during the procedure and 2 minutes afterwards, the ANOVA test revealed that all three groups were having statistically significant difference. Post hoc Bonferroni revealed that group 1 had the lowest saturation followed by group 2 and group 3. But in Figure 2B, ANOVA test revealed that there was no statistically significant difference between the groups in all the intervals of saturation when IM route was used. Reduction in $\mathrm{SPO}_{2}$ was statistically significant after both the invasive procedures in all the three readings

\section{Discussion}

The first step towards alleviating pain in neonates is to understand when they are in pain. It is indeed appalling that our medical fraternity continues to allow neonates to suffer pain for the sake of need when numerous proven, easy and cost-effective analgesic measures exist. There are no comprehensive and definite recommendations for their regular use in day to day clinical scenarios. Our study has been carried out for the same purpose. We have studied the effectiveness of 3 non-pharmacological methods during painful stimulus of Hepatitis B vaccination and intravenous blood sampling, over a period of six months involving 190 newborns divided into 3 groups. The demographic data analysed as shown in Table 2, shows that the baseline characteristics in all the three groups were similar.

Non-nutritive sucking is thought to produce analgesia through stimulation of orotactile and mechanoreceptors when a pacifier or nonlactating nipple is introduced into the infant's mouth and inhibiting nociceptive impulses from the periphery along the ascending fibres. A sweet taste of $25 \%$ dextrose sensation stimulates cortical areas related to the pleasure which helps in the release of endogenous opioids and endorphins which modulate the transmission of painful signals acting on dorsal horn interneuronal gateway regions ${ }^{[11]}$. Sucrose also was shown in 45 studies to be effective and safe in reducing newborns' procedural pain ${ }^{[12]}$.

Mekkaoui et.al showed that while $80 \%$ neonates did not cry during venepuncture when they received $30 \%$ glucose, milk or nipple (NNS), no baby cried after this painful procedure in the $30 \%$ glucose + nipple group ${ }^{[13]}$. Carbajal et al found that NNS had a better analgesic effect than administration of a sweet solution, but that there was a synergistic effect between sucking a pacifier and administration of a sugar solution ${ }^{[14]}$. The combination reduces pain, cry duration and heart rate changes, almost similar to effects of breast feeding ${ }^{[15,16,17]}$.

But few studies prove otherwise. According to Corbo et.al, NNS had no effect on respiratory rate or transcutaneous oxygen tension, but reduced the time of crying and the heart rate increase during invasive routine procedures ${ }^{[18]}$. Curtis et.al showed that neither sucrose nor pacifier was found to significantly affect FLACC score change or heart rate, but cry duration was reduced considerably, more in sucrose than in NNS group ${ }^{[19]}$. Lima et al. reported a $40 \%$ reduction in pain scores and a $70 \%$ reduction in crying time with oral glucose compared to NNS in 78 healthy newborns during immunization ${ }^{[20]}$.

Expressed breast milk though has some benefit on heart rate, cry duration, behavioural facial response and some validated pain assessment tool scores when compared to placebo, but when compared to sucrose $12.5 \%, 20 \%$ or $25 \%$ sucrose the rise in heart rate, percentage of time crying and pain scores were significantly higher in the breastmilk group ${ }^{[21]}$. Our study also shows that expressed breast milk though reduces cry duration and pain when compared to no intervention, it has relatively poor effect on cry duration, NIPS score and Heart rate changes when compared to 
dextrose or NNS with dextrose for intravenous sampling as shown in table 5 and 6.

All the three non-pharmacological measures taken, showed a dramatic improvement in the behavioural and physiological parameters for both the invasive procedures. During the intravenous procedure, majority in group 3 followed by group 2 and group 1 achieved a relaxed facial feature, absent crying, quiet state and relaxed posture after the intervention. All the neonates in 3 groups had relaxed breathing after the intervention.

During the intramuscular procedure, majority in group 2 and group 3 followed by group 1 achieved a relaxed facial feature, absent crying and relaxed posture after the intervention. Majority in group 3 followed by group 2 and group 1 achieved a quiet state after the intervention. Almost all the neonates in 3 groups had Relaxed breathing after the intervention as shown in table 3 and 4 .

The lack of effect on spo2 might be explained by new born infants having insufficient time to express facial responses to pain during the very short IM injection. Thus, we could not determine the most beneficial intervention in the intramuscular route as shown in table 4 . This was similar to the study done by Liaw et.al ${ }^{[22]}$. NIPS scores was significantly reduced in all three groups after the intervention individually.

In our study, infants' facial responses to pain and HR were also significantly influenced by their sleep/wake state before injections. During IV procedure, mean NIPS score for sleeping neonates and awake neonates were 0 and $2.59+1.96$ before the intervention. Mean NIPS score for sleeping neonates and awake neonates were $0.60+0.847$ and $1.08+1.214$ after the intervention. During IM procedure, mean NIPS score for sleeping neonates and awake neonates were 0 and $2.48+2.121$ before the intervention. Mean NIPS score for sleeping neonates and awake neonates were $0.20+0.406$ and $0.97+1.591$ after the intervention. In both before and after intervention, the NIPS scores were significantly lower among the sleeping neonates in both the procedures. The facial expression and thus NIPS score is more pronounced when the baby is awake during the painful procedure. This was also similar to the results obtained by Mathai et.al in 2006, Grunav RV and Craig KD in 1987 and Gibbins et.al in $2002^{[23,24,25]}$.

We are happy that we compared three non pharmacological measures for two painful invasive neonatal procedures unlike many other studies that have mainly used only one painful procedure. But our single-centre study has many limitations. Sick and extremely premature infants, who are more likely to undergo multiple painful procedures, were excluded, thus limiting the external validity of the study. Though our study included 60 babies in three groups, that was higher than most numbers in the studies conducted earlier, it is still less for validation purpose. We highlight the absence of local protocols to evaluate and treat neonatal pain at the institution where the data were collected. It is also a concerning fact that infant facial responses to pain as well as physiological responses and cry duration might have been influenced by multiple confounding factors, such as infant hunger or discomfort, temperament, sleep/wake state, and prior painful experiences. Another limitation was we did not consider the effect of OPV also given along with Hepatitis B vaccine to cause nullifying effects on the pain.

\section{Conclusion}

Vaccines are considered to be the most common source of iatrogenic pain in childhood. Nurses should be trained to assess pain score using a suitable scale before, during, and after the procedure and document it on the nursing flowsheet. We hope that more centers adopt neonatal pain relief policies incorporating these interventions. The combination of sucrose and NNS has both calming and pain-relieving properties and, therefore, can be used for a variety of diagnostic and therapeutic activities.

\section{List of abbreviations}

NIPS: Neonatal Infant Pain Scale

NNS: Non - nutritive sucking

HR: Heart rate

EBM: Expressed breast milk

\section{Conflict of Interest:}

Nil

\section{Funding:}

Nil

\section{Authors' contributions}

Study concept by PMV. Data analysed by MP. PMV performed the experiments and collected data.PMV and NP wrote manuscript. NP and PM gave technical support.

All authors have read and approved the initial manuscript.

\section{Acknowledgement}

I thank the nursing staff for their efforts and the parents of the babies who were willing to participate in the study.

\section{References}

[1] Puchalski M, Hummel P. The reality of neonatal pain. Advances in neonatal care. 2002 Oct 1;2(5):233-47.

[2] Anand KJ. Pharmacological approaches to the management of pain in the neonatal intensive care unit. Journal of Perinatology. 2007 May;27(1):S4-11.

[3] Anand KJ, Hickey PR. Pain and its effects in the human neonate and fetus. N Engl j Med. 1987 Nov 19;317(21):1321-9.

[4] Duerden EG, Grunau RE, Guo T, Foong J, Pearson A, Au-Young S, Lavoie R, Chakravarty MM, Chau V, Synnes A, Miller SP. Early procedural pain is associated with regionally-specific alterations in thalamic development in preterm neonates. Journal of Neuroscience. 2018 Jan 24;38(4):878-86.

[5] Grunau RE. Neonatal pain in very preterm infants: longterm effects on brain, neurodevelopment and pain reactivity. Rambam Maimonides medical journal. 2013 Oct;4(4).

[6] Akuma AO, Jordan S. Pain management in neonates: a survey of nurses and doctors. Journal of advanced nursing. 2012 Jun;68(6):1288-301

[7] Pölkki T, Korhonen A, Laukkala H, Saarela T, Vehviläinen-Julkunen K, Pietilä AM. Nurses' attitudes and perceptions of pain assessment in neonatal intensive care. Scandinavian journal of caring sciences. 2010 Mar;24(1):49-55. 
[8] Hsieh KH, Chen SJ, Tsao PC, Wang CC, Huang CF, Lin CM, Chou YL, Chen WY, Chan IC. The analgesic effect of non-pharmacological interventions to reduce procedural pain in preterm neonates. Pediatrics \& Neonatology. 2018 Feb 1;59(1):71-6.

[9] Anand KJ. Pain assessment in preterm neonates. Pediatrics. 2007 Mar 1;119(3):605-7.

[10] Lawrence J, Alcock D, McGrath P, Kay J, MacMurray SB, Dulberg C. The development of a tool to assess neonatal pain. Neonatal Netw. 1993;12(6):59-66.

[11] Gibbins S, Stevens B. Mechanisms of sucrose and nonnutritive sucking in procedural pain management in infants. Pain Research and Management. 2001 Jan 1;6.

[12] Stevens B, Yamada J, Ohlsson A. Sucrose for analgesia in new born infants undergoing painful procedures. Cochrane Database Syst Rev 2010;1: CD001069, 1e114.

[13] Mekkaoui N, Issef I, Kabiri M, Barkat A. Analgesic effect of $30 \%$ glucose, milk and non-nutritive sucking in neonates. J Pain Res. 2012;5:573-7.

[14] Carbajal R, Lenclen R, Gajdos V, Jugie M, Paupe A. Crossover trial of analgesic efficacy of glucose and pacifier in very preterm neonates during subcutaneous injections. Pediatrics. 2002;110:389-393.

[15] Bueno M, Yamada J, Harrison D, et al. A systematic review and meta-analyses of nonsucrose sweet solutions for pain relief in neonates. Pain Res Manag. 2013;18(3):153-61.

[16] Harrison D, Bueno M, Yamada J, Adams-Webber T, Stevens B. Analgesic effects of sweet-tasting solutions for infants: current state of equipoise. Pediatrics 2010;126:894e902.

[17] Blass EM, Watt LB. Suckling-and sucrose-induced analgesia in human newborns. PAIN®. 1999 Dec 1;83(3):611-23.
[18] Corbo MG, Mansi G, Stagni A, et al. Nonnutritive sucking during heel stick procedures decreases behavioural distress in the new born infant. Biol Neonate 2000;77:162-7.

[19] Curtis SJ, Jou H, Ali S, Vandermeer B, Klassen T. A randomized controlled trial of sucrose and/or pacifier as analgesia for infants receiving venipuncture in a paediatric emergency department. BMC Pediatr 2007; 7:27.

[20] Lima, A.; Santos, V.; Nunes, M.; Barreto, J.; Ribeiro, C.; Carvalho, J.; Ribeiro, M. Glucose solution is more effective in relieving pain in neonates than non-nutritive sucking: A randomized clinical trial. Eur. J. Pain 2017, 21, 159-165.

[21] Shah PS, Herbozo C, Aliwalas LL, Shah VS. Breastfeeding or breast milk for procedural pain in neonates. Cochrane Database of Systematic Reviews. 2012(12).

[22] Liaw JJ, Zeng WP, Yang L, Yuh YS, Yin T, Yang MH. Nonnutritive sucking and oral sucrose relieve neonatal pain during intramuscular injection of hepatitis vaccine. Journal of pain and symptom management. $2011 \mathrm{Dec}$ 1;42(6):918-30.

[23] Mathai S, Natrajan N, Rajalakshmi NR. A comparative study of non-pharmacological methods to reduce pain in neonates. Indian pediatrics. 2006 Dec 1;43(12):1070.

[24] Grunau RV, Craig KD. Pain expression in neonates: facial action and cry. Pain. 1987 Mar 1;28(3):395-410.

[25] Gibbins S, Stevens B, Hodnett E, Pinelli J, Ohlsson A, Darlington G. Efficacy and safety of sucrose for procedural pain relief in preterm and term neonates. Nursing research. 2002 Nov 1;51(6):375-82. 